\title{
Paradoxical Sleep Deprivation: neurochemical, hormonal and behavioral alterations. Evidence from 30 years of research
}

\author{
SERGIO TUFIK, MONICA L. ANDERSEN, LIA R.A. BITTENCOURT and MARCO T. DE MELLO
}

\author{
Disciplina de Medicina e Biologia do Sono, Departamento de Psicobiologia, Universidade Federal de São Paulo \\ Escola Paulista de Medicina (UNIFESP/EPM), Rua Napoleão de Barros, 925, Vila Clementino, 04024-002 São Paulo, SP, Brasil \\ Manuscript received on July 25, 2008; accepted for publication on April 3, 2009; \\ presented by LUIZ R. TRAVASSOS
}

\begin{abstract}
Sleep comprises approximately one-third of a person's lifetime, but its impact on health and medical conditions remains partially unrecognized. The prevalence of sleep disorders is increasing in modern societies, with significant repercussions on people's well-being. This article reviews past and current literature on the paradoxical sleep deprivation method as well as data on its consequences to animals, ranging from behavioral changes to alterations in the gene expression. More specifically, we highlight relevant experimental studies and our group's contribution over the last three decades.
\end{abstract}

Key words: sleep, sleep deprivation, rebound, dopamine, erection, corticosterone, memory.

\section{INTRODUCTION}

Sleep occupies approximately one-third of a person's life, but its impact on health and medical conditions remains partially unrecognized. The prevalence of sleep disorders is increasing in modern societies, where constant exposure to artificial light and interactive activities, such as television and the internet, combine with social and economic pressures to shorten the time spent asleep.

Most sleep disorders, such as sleep apnea, periodic leg movements disturbance, restless legs syndrome, jet lag, and insomnia, lead to sleep deprivation. Sleep deprivation per se represents a common type of stress that can have harmful physiological consequences, possibly leading to death in experimental animals (Rechtschaffen et al. 1983). Chronic insomnia leads to persistent tiredness and frustration due to lack of energy. Respiratory pathological conditions and other medical condi-

In commemoration of the $75^{\text {th }}$ anniversary of Escola Paulista de Medicina / Universidade Federal de São Paulo. Correspondence to: Dr. Sergio Tufik

E-mail: stufik@psicobio.epm.br tions that affect sleep have potentially serious complications that may reduce life expectancy.

Disturbances in the sleep-wake rhythm and sleep deprivation are increasingly frequent due to events that are progressively more common in modern life in more developed countries (Spiegel et al. 1999). Many subjects can be chronically sleep-deprived as a result of their current lifestyle (Miró et al. 2002). Sleep deprivation can lead to traffic accidents due to fatigue and alterations in the biological rhythm. Indeed, $16 \%$ of Brazilian interstate bus drivers reported sleepiness while driving, with an average of eight naps/trip (De Mello et al. 2000 ), and $38 \%$ of those drivers have been diagnosed with obstructive sleep apnea (Santos et al. 2004). Recently, a new legislation was approved that will require new medical and psychological examinations for all Brazilian drivers. These examinations will be initially carried out by a physician who specializes in traffic medicine. As a result, it can be expected a reduction in the number of accidents and deaths resulting from sleepy 
driving (De Mello et al. 2009). An epidemiological study performed by the Department of Psychobiology of Unifesp in the city of São Paulo has shown that, in 1995, 27.6\% (1.7 million) of inhabitants of São Paulo complained of difficulty in staying asleep. Furthermore, habitual snoring was the most common complaint and was reported by about $20 \%$ of the interviewees (Pires et al. 2007). In 2007, obstructive sleep apnea syndrome was found in $32.8 \%$ of the population of São Paulo, Brazil (S. Tufik et al., unpublished data).

Sleep has a cyclical or episodic phase that alternates with wakefulness. An important characteristic of sleep that differentiates it from most of other states of altered consciousness is that it is promptly reversible.

Electrophysiological studies in the 1950s demonstrated that there are two main states of sleep: non-rapid eye movement (NREM) and rapid eye movement (REM). The lighter stages of NREM sleep (phase 1 and 2) appear first and often alternate with brief episodes of wakefulness before the deeper NREM sleep stages set in. NREM sleep, particularly its deeper stages (phase 3 and 4), predominate early in the night, while REM sleep occurs at approximately 90 -minute intervals. There are usually four to six sleep cycles each night, and, as the night progresses, the REM episodes become longer, and NREM episodes become both shorter and lighter. NREM sleep is recognized by its low frequency and high amplitude, in addition to the presence of sleep spindles and hypotonia as registered on an electroencephalogram (EEG).

Research suggests that REM sleep enables the establishment of behavior patterns and emotional responses. During REM sleep, the information obtained during wakefulness appears to be reprocessed and integrated into existing neural templates, so that future responses can be modified or matured to reflect both the experience of the individual and the inherent potential (Jouvet 1998). The electrophysiological features of REM sleep include recording of a wide range of desynchronized EEG frequencies, loss of EMG activity and rapid eye movement. The EEG reflects the intense cerebral cortical activity that distinguishes REM from NREM sleep, but the similarity of REM to the EEG of wakefulness has led it to be called "paradoxical" sleep (PS). This term has been adopted for the description of animals in this review.
A common irregular sleep-wake schedule is as follows: restricting sleep during a working week, leading to an accrual of sleep debt, and repaying the debt by sleeping longer on weekends. During these nights, there is high sleep efficiency, short sleep latency, and increased duration of stages 3 and 4 NREM sleep. Waking later in the morning, however, causes a phase delay the next day, which is often followed by an early wake-up time at the start of the working week. The duration of sleep is thereby considerably shortened, and sleep deprivation begins again (Shneerson 2000).

The homeostatic sleep drive appears to control NREM rather than REM sleep. Sleep is normally entered through NREM rather than REM sleep in adults, and an increase in the homeostatic drive will increase the duration and depth of NREM sleep at the expense of REM sleep. NREM sleep provides time for restorative processes within the central nervous system (CNS) and other parts of the body. Overall, NREM sleep appears to be a phase in which energy is conserved and in which both the CNS and other systems are able to either recover from the activity of the previous episode of wakefulness or to prepare for the next episode. Currently, most sleep deprivation occurs in the REM phase, which occurs during the last half of the total sleep session. It is in this phase that most restorative processes take place.

There are several different approaches that may be taken to understand the functional properties of PS. A common procedure involves deprivation of PS in various organisms and subsequent observation of behavioral and physiological changes. Thus, most studies of sleep deprivation focus on PS deprivation (PSD). The present paper reviews various studies that have utilized the PSD strategy.

\section{PSD METHODS}

The PSD technique entails an arousal of experimental animals by external stimulation at the onset of each PS period. Most of the instrumental methods utilized to induce PSD in animals are modifications of a single method developed by Jouvet et al. (1964) for cats, known as the flower pot technique. Shortly afterward, this method was adapted to rats by Cohen and Dement (1965). The method consists of placing a rat on a narrow platform (6.5 $\mathrm{cm}$ in diameter) surrounded by water. Once ha- 
bituated to this situation, the animals can obtain slow wave sleep (SWS), whereas PS is restricted. The loss of muscle tone associated with the onset of PS results in the animals touching the water and awakening. Information regarding the efficiency of the technique indicates that the degree of PSD may vary considerably. The diameter of the platform relative to the size of the animal seems to be mainly responsible for this variability (Steiner and Ellman 1972, Mendelson et al. 1974, Hicks et al. 1977). This method has been criticized because it submits the animal to additional adverse stimuli that could induce several of the effects observed after PSD.

To attenuate the effects of these intervening variables, the multiple platform method was developed. In this paradigm, one rat is placed inside a large water tank containing seven platforms, which eliminates the restriction of movement and allows the animal to ambulate (Van Hulzen and Coenen 1981). This method was further modified in an attempt to eliminate the social isolation experienced by the animal in both the flower pot and the multiple platform techniques (Nunes and Tufik 1994a). In this paradigm, 10 animals on 18 narrow or wide platforms (as a control for the deprivation environment) are used, thus avoiding both social isolation and movement restriction. This technique is procedurally simple and allows for a large number of animals to be sleep deprived simultaneously. In 2000, Suchecki and Tufik proposed the modified multiple platform method (MMPM) using socially stable groups (10 animals from one cage) instead of animals coming from several cages. The results of this work suggest that the stress-related variables of the MMPM can be attenuated in stable groups.

Regarding the control group, most attention has been focused upon the selection of control subjects. When an animal is placed on a small platform in the water tank, many events happen in addition to PSD. For example, the animal is exposed to a good deal of stress. Control groups usually consist of either cage-control animals or rats placed on a wide platform $(14 \mathrm{~cm}$ in diameter) under the same environmental conditions. This large platform enables the animal to curl up and experience both SWS and PS without contacting the water. It is commonly used as a control for the confounding factors inherent to this technique. Although this control may be appropriate to address most of the confounding factors, it remains controversial (Landis 1996, Machado et al. 2004). Indeed, when exposed to the MMPM, the animals placed on the wide platforms exhibit adrenal hypertrophy similar to that produced by placement on narrow platforms (Nunes and Tufik 1994a). In addition, a wide platform induces some degree of PSD, as reflected by augmented rebound during the recovery period (Machado et al. 2004). In the rotation disk method proposed by Rechtschaffen et al. (1983), nonspecific concomitants of this technique are controlled by a "yoked" control animal, which is concurrently aroused with the experimental animal (Van Hulzen and Coenen 1979). In the disk method, whenever the experimental rat begins to sleep or enters a specific sleep stage, the disk automatically rotates, which awakens the experimental rat and forces both rats to walk in the opposite direction to the disk's rotation to avoid the water (Rechtschaffen et al. 1983). Another proposed control group for the deprivation environment consisted of animals lying on a grid placed inside the water tank (Suchecki and Tufik 2000). In this situation, the animals could lie down without falling into the water, although their tails might have done so. The data suggest that this is a good control; however, sleep rebound was observed. The animal is exposed to a similar environment without, in theory, being submitted to PSD. It is important to note that only social stable animals were placed on the grid, as described in the same paper.

Recently, we proposed a paradigm for chronic sleep restriction in rats in which the animals are submitted to a schedule of $18 \mathrm{~h}$ of sleep deprivation with a $6 \mathrm{~h}$ sleep window for 21 days (Machado et al. 2005). As a result of this restriction, there was a complete suppression of PS and loss of SWS, which were partially compensated during the $6 \mathrm{~h}$ sleep window. Of note, a major sleep consolidation was observed during the 6 h sleep opportunity, reflected by an intense reduction of awakenings.

\section{REBOUND SLEEP}

The importance of PS to an organism can be partly deduced from recovery sleep after deprivation. PSD invariably leads to a striking compensation phenomenon, known as the PS rebound. According to Van Luijtelaar 
and Coenen (1984), rebound sleep is determined both by recovery processes and circadian timing. The increases (above baseline) in sleep duration during the recovery from sleep deprivation are usually only a fraction of the sleep time that was lost. Because it is widely assumed that sleep is homeostatically regulated, many believe that lost sleep is compensated by "intense sleep" that satisfies the unfulfilled sleep need in a relatively short period (Rechtschaffen et al. 1999). In addition to an increased sleep duration, the latency to the first PS episode is shortened, and the time spent in PS is lengthened (Dement 1960, Mendelson et al. 1974, Morden et al. 1967). Sleep rebound is also observed in rats submitted to different stress modalities (Tufik et al. 1995, Palma et al. 2000, Papale et al. 2005). For instance, immobilization led to a rebound of SWS and PS, whereas cold stress produced an exclusive rebound of SWS and foot shock promoted sustained alertness during the animal's resting period. Together, these observations indicate that different stimuli alter the sleep pattern in distinct manners (Palma et al. 2000).

\section{EFFECTS OF PSD ON BRAIN NEUROTRANSMITTERS}

The nature of PSD techniques has led to much discussion about its consequences (Vogel 1975, Ellman et al. 1978). Most of the consequences are believed to be controlled by central neurotransmitter systems. To that end, many neurotransmitters, such as catecholamines, acetylcholine, serotonin, and GABA, have been associated, either alone or in trans-synaptic relationships, with several behavioral alterations. These associations suggest that the behavioral alterations observed after PSD result from deprivation-induced alterations in brain neurotransmitter function.

Evaluation of experiments that employed the water tank PSD technique indicated that this procedure alters some behaviors that can be induced by drugs that act on neurotransmitter systems. The neurochemical basis of the constellation of behavioral changes that follow PSD is not completely clear, but many observations suggest a major role for central dopamine (DA).

In 1978, Tufik and colleagues reported that PSD resulted in augmented apomorphine-induced aggression and several stereotypical behaviors, including biting, rearing and hypothermia in rats. These behaviors oc- curred with greater magnitude and with smaller doses of apomorphine in the PSD rats when compared with control animals, and have been used to study the responsiveness of DA receptors to agonist agents. The authors suggested that the findings led to the belief that PSD induced supersensitivity of brain DA receptors. Shortly thereafter, further experiments supported the hypothesis that the exacerbated aggressiveness elicited by apomorphine in PSD rats was due to a state of supersensitivity of post-synaptic dopaminergic receptors in the brain (Tufik 1981a). This study showed that, in addition to apomorphine, PSD intensified the effects of two other dopaminergic agonists (bromocriptine and piribedil). The second finding of this study was that co-administration of PSD and an injection of haloperidol 24h before apomorphine administration induced more aggressive behavior when compared to that of rats that were only subjected to PSD, indicating that apomorphine was significantly more active in rats submitted to the double treatment. Finally, administration of haloperidol $2 \mathrm{~h}$ before apomorphine administration blocked the aggressive behavior in rats submitted either to PSD alone or to PSD and an injection of haloperidol $24 \mathrm{~h}$ previously. This result further supports the hypothesis that the postsynaptic dopaminergic receptors are in a state of supersensitivity.

Alternatively, these data may indicate that presynaptic dopaminergic activity was augmented by the above-described treatment regimen. Ghosh et al. (1976) reported that striatal DA levels were increased after PSD, raising the hypothesis that the hyperresponsiveness to apomorphine after PSD could merely reflect an excess of agonistic substances at the post-synaptic receptors. Tufik (1981b) reported that such a response was not due to a modification in DA turnover or levels, since it was demonstrated that animals treated with L-DOPA and injected with apomorphine failed to show aggressive behavior. However, PSD rats pre-treated with $\alpha$-methylpara-tyrosine continued to show an intense response to DA agonists, suggesting that presynaptic mechanisms are not of prime importance for this augmented PSDinduced response (Tufik 1981b). In a later study, it was shown that the increase in apomorphine-induced stereotypy and aggression in PSD rats was reversed by DA agonist pretreatment (Troncone et al. 1988). 
Interaction between the DA and norepinephrine (NOR) systems, which was achieved through modulation of the DA drug regimen, induced aggressive behavior in PSD rats that were pretreated with adrenergic drugs. This result indicates that NOR had a slight inhibitory action on the aggressiveness elicited by dopaminomimetic agents in PSD rats (Troncone and Tufik 1991). The reduced level of aggression could be due to a small increase in DA release associated with a lack of secondary noradrenergic inhibition rather than to a lack of NOR activity. This situation would evidence a role for beta-adrenoceptors in the modulation of this behavior. This proposition is supported by the observation that a reduced number of $\beta$-adrenoceptors are present in the cortex of rats submitted to PSD (Mogilnicka et al. 1986). This tissue has been shown to be subsensitive to NOR, which is reflected by evaluation of in vitro cyclic-AMP synthesis (Troncone et al. 1986). Autoradiographic analysis shows a generalized but regionally heterogeneous reduction in the number of $\beta$ receptors subtypes in the brain, as well as clear trends of down- and up-regulation of $\alpha_{1}$ and $\alpha_{2}$ sites, respectively (Hipólide et al. 1998).

In another set of experiments that evaluated PSD and DA, yawning behavior was used to assess the sensitivity of DA and acetylcholine receptors in rats submitted to PSD (Tufik et al. 1987). The results demonstrated that PSD significantly decreased the yawning response induced by presynaptic doses of apomorphine and small doses of physostigmine and pilocarpine, suggesting that PSD induces subsensitivity of presynaptic DA receptors and/or postsynaptic acetylcholine receptors.

A large body of evidence indicates that drug-induced yawning in rats is a behavioral consequence of dopaminergic autoreceptor stimulation, which results in decreased DA synthesis and release, impaired dopaminergic transmission, and consequent removal of the inhibition of cholinergic neurons exerted by DA neurons (Yamada and Furukawa 1981). Thus, yawning behavior seems to involve both dopaminergic inhibition and cholinergic activation. By evaluating animals after a recovery period of $24 \mathrm{~h}$, Neumann et al. (1990) observed that, while apomorphine-induced yawning was still significantly reduced, pilocarpine-induced yawning had returned to normal, suggesting that PSD alters these systems differently. It seems that interference on the dopa- minergic system occurs more strongly and at an earlier time than on cholinergic system.

With respect to the evidence mentioned above, these findings led to the hypothesis that PSD induces an upregulation of dopaminergic receptors (Tufik et al. 1978, 1987). However, because apomorphine is a mixed $\mathrm{D}_{1} / \mathrm{D}_{2}$ agonist, it was not possible to determine from those experiments which subtype of dopaminergic receptor is unregulated after PSD. Nunes et al. (1994b) used autoradiographic analysis to address this question. They found that PSD increased $\mathrm{D}_{2}$ but not $\mathrm{D}_{1}$ receptor binding in the brain, suggesting that the unregulated $\mathrm{D}_{2}$ receptors are responsible for the previously reported changes in apomorphine-induced behaviors after PSD. An increase in DA release in the PSD group exerts greater dopaminergic-mediated effects due to upregulation of DA receptors in the striatum of PSD rats compared to control group (Farooqui et al. 1996). This finding further supports the early studies on behavioral effects of dopaminergic stimulants in PSD animals (Tufik et al. 1978, Clark et al. 1987, Asakura et al. 1992). However, the decrease in yawning behavior induced by cholinergic agonists (Tufik et al. 1987) led to an investigation of cholinergic receptors in animals submitted to PSD. Again, an autoradiographic study showed that PSD resulted in a generalized down regulation of $\mathrm{M}_{2}$ type muscarinic receptors in the brain of a rat, corroborating the notion that pontine $\mathrm{M}_{2}$-type receptors may participate, but do not necessarily play an integral role, in the development of PSD effects (Nunes et al. 1994c).

Some evidence suggests that PSD enhances serotonergic transmission. Bearing this in mind, direct examination of 5-HT receptor binding after PSD was restricted to early studies that used a non-selective ligand $[3 \mathrm{H}] 5-\mathrm{HT}$ in a limited number of brain areas. These studies showed that binding to $5-\mathrm{HT}_{1 \mathrm{a}}$ was not significantly altered by PSD in any of the brain areas examined. However, there was an overall trend toward decreased binding in the target paradoxically sleep deprived group. The same phenomenon occurred with serotonin transporter (SERT) binding after PSD. The frequency of ligand binding to $5 \mathrm{HT}_{2}$ sites was generally decreased after PSD in 81 brain areas, and this reduction was more pronounced in the sleep recovery period (Hipólide et al. 2005). 
Orexins are a newly discovered class of neuropeptides that regulate feeding and vigilance. Initially recognized for their importance in appetite control, orexins (also called hypocretins) are also involved in regulating sleep, arousal, and cardiovascular function. Loss of orexin appears to be the primary cause of narcolepsy (Kilduff and Peyron 2000, Sutcliffe and de Lecea 2002). Expression of orexins is restricted to a discrete region of the hypothalamus, but the terminal projections of orexin-producing cells are widely distributed throughout the brain. In the rat, orexin induces a dose-dependent increase in wakefulness when it is injected intracerebroventricularly (Piper et al. 2000). The densest projection of orexinergic cells in the rat is in the locus coeruleus (Horvath et al. 1999), the noradrenergic output that favors cortical arousal of waking and opposes PS-associated arousal (Hobson et al. 2000, Aston-Jones et al. 2001).

Pedrazzoli et al. (2004) measured hypocretin levels at 6 and 96h after PSD and following 24h of rebound. PSD was found to increase cerebral spinal fluid orexin-1 collected at zeitgeber time (ZT) 8, but not at ZT0. Decreased cerebral spinal fluid orexin levels were also observed at ZT8 after $24 \mathrm{~h}$ of PS rebound. These results suggest that PSD activates and that rebound inhibits the orexin system. The authors suggested that increased orexin tone during PSD might be important for some of the effects of PSD, such as antidepressant effects, hyperphagia, and increased sympathetic activity. Another experiment performed by D'Almeida et al. (2005) showed that the level of prepro-orexin (the precursor of both forms of orexin) mRNA increased by $30 \%$ at 96 hours after in the PSD group and by $88 \%$ after 24 hours in the rebound group relative to controls. Sleep deprivation produced a heterogeneous effect on brain mRNA levels of both orexin receptors (OXR). The $\mathrm{OX}_{1} \mathrm{R}$ mRNA levels increased in more than 30 different regions, particularly in the amygdala and hypothalamus in the rebound group compared to control and sleep deprived groups. Changes in $\mathrm{OX}_{2} \mathrm{R}$ mRNA levels were also seen only in the sleep rebound group, but the levels were decreased rather than increased, and they were predominantly confined to the cerebral cortex. These observations suggest that continued sleep deprivation progressively increases prepro-orexin mRNA levels and alters orexin receptor expression. These effects are not immediately reversed by sleep recovery, indicating a lasting activation of the orexinergic system. Collectively, the overall changes in brain neurotransmitters after PSD may indicate that the mechanisms involve in the process of sleep recovery.

\section{PSD AND GENE EXPRESSION}

Sleep deprivation of short duration or prolonged for several days alters the expression of distinct categories of genes in the brain, including immediate-early genes, such as transcription factors; genes that encode proteins involved in metabolic processes, neuronal plasticity, and the stress response; and genes that encode neurotransmitters, hormone receptors and transporters, and enzymes (Cirelli et al. 2004, Cirelli 2006, Terao et al. 2008, Maret et al. 2007). In addition, it has been shown that the pattern of changes is consistent across species (Cirelli 2002) and in distinct brain regions (Cirelli et al. 2004, Terao et al. 2008).

Through the use of microarrays to evaluate the expression of $>30,000$ transcripts, we recently identified a total of 78 unique transcripts that were differentially expressed in animals submitted to PSD relative to controls (Guindalini et al. 2009). These differentially expressed transcripts include genes from many functional classes, including metabolic processes, the circadian sleep-wake cycle, the response to a stimulus, regulation of cell proliferation, and signaling pathways. After $24 \mathrm{~h}$ of sleep rebound, expression of $\sim 61.5 \%$ of the sleep deprivation-regulated transcripts was detected as being differentially expressed in the recovery period, resembling the gene expression pattern of the controls, relative to the PSD group. However, as occurs with a number of behavioral and physiological parameters, the expression levels of the remaining $38.5 \%$ of transcripts were among the levels observed for control and sleep-deprived animals, suggesting that a longer recovery period is necessary to completely reverse the effects of prolonged PSD. Noteworthy, DNA damage is an important step in events leading to genomic instability. We recently conducted an experiment demonstrating that DNA damage was preferentially induced in the brain and blood cells of paradoxically sleep deprived rats, whereas no detectable changes were observed in 
the liver or heart cells (Andersen et al. 2009). This study represents a relevant contribution to the understanding of the potential health risks associated with sleep deprivation. Collectively, these results suggest that PSD elicits a pattern of gene expression that is similar to those observed for other paradigms of sleep deprivation, and that PSD has characteristics that might be related to the regulation of PS. In addition, $24 \mathrm{~h}$ of sleep recovery was not sufficient for complete reversal of the effects caused by prolonged periods of PSD of a number of behavioral and physiological parameters (Andersen et al. 2005a, Antunes et al. 2006).

Interestingly, Maret and colleagues demonstrated that sleep deprivation induced a larger number of transcriptional changes in the liver than in the brain, suggesting that sleep deprivation might have a strong effect on peripheral tissues and/or that the brain might be protected from major changes in transcription (Maret et al. 2007). This study corroborates our results, which indicate that there is less variation in the gene expression in the brain compared to other tissues, such as blood and cavernosum, following PSD (Lee et al. 2009).

\section{PSD AND BEHAVIORAL ALTERATIONS}

\section{YAWNING}

Apart from the constellation of behavioral and neuropharmacological consequences of PSD, yawning is particularly interesting because it can be elicited by several cholinergic agonists (Urbá-Holmgren et al. 1977, Wood et al. 1979), such as low doses of dopaminergic agonists (Mogilnicka and Klimek 1977) and polypeptides such as $\alpha$-MSH and ACTH (Ferrari et al. 1963, Yamada and Furukawa 1981, Lobo et al. 1990). This finding suggests that multiple neurotransmitter systems modulate this behavior. PSD for 96h results in nearly complete suppression of yawning induced by dopaminergic and cholinergic agonists (Tufik et al. 1987). Since the activity of both of these neurotransmitter systems is also altered by stress (De Kloet 1991), animals were chronically exposed to different stress modalities. The evaluation of yawning induced by dopaminergic and cholinergic drugs showed that immobilization caused suppression of this behavior, whereas forced swimming and foot shock increased the number of yawns. These findings suggest that yawning is differentially altered by constant and intermittent stressors (Tufik et al. 1995).

As these stressful manipulations altered drug-induced yawning, Hipólide et al. (1999) investigated the effects of single and repeated treatments with a synthetic glucocorticoid, dexamethasone (DEXA) on apomorphine- and pilocarpine-induced yawning in rats. Neither single nor repeated treatment with DEXA altered apomorphine-induced yawning. A single injection of DEXA, however, caused an increased number of yawns induced by pilocarpine. Repeated treatment with DEXA led to a decreased number of yawns induced by pilocarpine. The authors concluded that dopaminergic and cholinergic systems are distinctly altered by DEXA in terms of yawning behavior. Furthermore, yawning behavior was evaluated to examine whether concomitant treatment with PSD and DA agonists could reverse PSD effects (Lobo et al. 1995), as observed with stereotypy and aggressiveness (Troncone et al. 1988).

More recently, the effects of acute and chronic $\Delta^{8}$. and $\Delta^{9}$-tetrahydrocannabinol $\left(\Delta^{8}\right.$ and $\Delta^{9}$-THC) were examined on yawning induced by pilocarpine or apomorphine. The data suggest that cannabinoid agonists inhibited yawning induced by cholinergic and dopaminergic agonists. In addition, the increased frequency of spontaneous yawning following cessation of chronic administration of a cannabinoid agonist may be of importance as a withdrawal sign for these drugs (NakamuraPalacios et al. 2002). Cannabis also induces aggressive behavior in PSD rats. This effect is probably related to brain catecholamines, as DA may play an agonist role and NOR an inhibitory role (Carlini et al. 1977).

\section{COGNition}

Sleep has roles in learning and memory processes at several levels (Stickgold and Walker 2007). Two main lines of evidence support this hypothesis in rodents. Firstly, PS following the acquisition of learning tasks leads to increases in the number and duration of episodes and PS density (Smith and Wong 1991). Secondly, many studies report an impaired acquisition when PSD is performed before or after the training period for several learning tasks (Smith 1985, Silva et al. 2004a, b). PSD performed before the training period resulted in acquisition deficits that were not task-specific. This is 
because the procedure affected inhibitory avoidance and an appetite-motivated task (Stern 1971). In contrast, using appetitive motivation, no effect on accuracy of Tmaze discrimination was found with PSD (Hicks and Paulus 1973). The nature of the task might be one factor that accounts for these discrepancies. To determine whether PSD administered prior to training would have differential effects on two aversively motivated tasks (classical conditioning of fear and inhibitory avoidance), Bueno et al. (1994) submitted rats to PSD, and the rats were trained on a double aversively motivated task. The data show that PSD administered 24 or $72 \mathrm{~h}$ before the training session had no effect on either task. However, when the period of deprivation was extended to $96 \mathrm{~h}$ before the training session, acquisition of inhibitory avoidance was impaired, but no effect on classically conditioned fear was observed. Thus, the authors concluded that PSD had differential effects on the two tasks, both aversively motivated and trained at the same time and under the same conditions. Moreover, the study on the effects of pharmacological interference with the cholinergic system on PSD-induced memory impairment show that activation of this system during the period of deprivation can prevent memory deficits induced by PSD (Bueno et al. 2000). Later data from our group suggest that proactive learning/memory deficits induced by PSD could be attributed to altered M1 binding either immediately after PSD (when avoidance training occurs) or after sleep recovery (when acquisition/retention are tested) (Moreira et al. 2003).

In 2000, Silva and Frussa-Filho proposed the use of the plus-maze discriminative avoidance task (PMDAT), which is a behavioral paradigm that has the advantage of independently evaluate learning, memory, and anxiety as well as motor activity. PM-DAT complies with ethical protocols since there is no foot shock, which is imposed by classical avoidance tests. Considering the effects of PSD in mice submitted to the PMDAT (Silva et al. 2004b), pre-training PSD-induced anxiogenic and hypolocomotor effects were observed in the training session, but they did not modify the acquisition of the task.

Recently, Alvarenga et al. (2008) investigate the effects of PSD for 96h on the learning/memory processes in rats submitted to the PM-DAT, which simulta- neously evaluates learning, memory, anxiety and motor function. Our results demonstrate that PSD induced impairment in the acquisition, consolidation and retrieval of a discriminative avoidance task. In the three experimental conditions, a $24 \mathrm{~h}$ sleep recovery period was effective in abolishing the PSD cognitive effects, but was ineffective in modifying them per se. In addition, PSD produced significant alterations in anxiety-like behavior and locomotor activity, which may be related to the impairment in retrieval (but not in acquisition or consolidation). This study strengthened the critical role of PS (but not sleep rebound) in all the phases of learning and memory formation. In addition, it suggests that PSD effects on acquisition and consolidation do not seem to be related to other behavioral alterations induced by this procedure.

\section{LOCOMOTOR AND ANXIETY-LIKE BEHAVIOR}

Regarding the effect of PSD on locomotor activity (Tufik and Silveira-Filho 1983, Frussa-Filho et al. 2004, Andersen et al. 2005b, Perry et al. 2007), some studies have focused on locomotor activity and sleep patterns. Consequently, speculations about the effect of the exercise on sleep due to sleep deprivation have been raised (Martins et al. 2001).

From our data, it can be assumed that PSD induced significant but heterogeneous effects in animals. For instance, PSD increased grooming, but it had no effect on stereotyped behaviors, locomotion, or the elevated plus maze test. Importantly, it significantly decreased rearing behavior, which is associated with potentiation of stereotypy and exploratory activity (Andersen et al. 2005b). In addition, another study showed that single platform PSD rats had reduced locomotor activity and augmented anxiety-like behavior (Suchecki et al. 2002). Recently, Martins and colleagues (2008) pointed out that PSD increased gnawing behavior undirected to feeding, supporting the view that spontaneous oral stereotypy, rather than hunger, is the major cause of increases in food removed from feeders in rats deprived of sleep for up to 96 hours.

In mice, sleep deprivation for $72 \mathrm{~h}$, achieved by the multiple platform method, induces increased anxiety as evaluated by the PM-DAT and in the conventional plusmaze (decreased time spent in the open arms) (Silva et 
al. 2004a, b), as well as in the open-field test (decreased in central locomotion frequency). This anxiogenic effect was not observed after $24 \mathrm{~h}$ of sleep deprivation.

\section{SEXUAL BeHAVIOR}

As mentioned, PSD results in several behavioral alterations in rats that are likewise induced by dopaminergic agonists (Tufik et al. 1978, 1987, Andersen and Tufik 2005); however, there is some controversy about the effect of PSD on sexual behavior. DA plays a key role in the modulation of this behavior (Bitran and Hull 1987). Morden and co-workers (1968) reported increased sexual performance in PSD male rats. In another study, however, four days of PSD did not significantly alter male sexual performance (Hicks et al. 1991).

In this context, we have consistently demonstrated the facilitatory effects of PSD on genital reflexes (penile erection, or PE, and ejaculation, or EJ) in rats (Andersen et al. 2000). The data revealed that only PSD rats exhibited PE and EJ behaviors, which were absent in control animals. Indeed, combined administration of PSD and cocaine elicited genital reflexes much more markedly than did administration of PSD or cocaine alone (Andersen and Tufik 2002). Although a number of factors are involved in a complex phenomenon such as PE, the authors suggest that the previously documented DA receptor supersensitivity induced by PSD may be an important contributor to the potentiation of genital reflexes by cocaine after sleep deprivation. Importantly, other dopaminergic drugs, such as cocaine (Andersen et al. 2004a, b), methamphetamine (Andersen et al. 2003a) and apomorphine (Andersen et al. 2003b), also increased the effects of PSD on genital reflexes in both young (Andersen et al. 2003c) and old male rats (Andersen et al. 2002, 2004a).

The period of exposure to PSD seems to interfere with the responses of genital reflexes. After $24 \mathrm{~h}$ of PSD followed by cocaine administration, adult animals started to display PE and EJ, which peaked at 96h of PSD. More than 96h of PSD decreased genital reflexes, as observed at 120 and 144 hours (Andersen et al. 2003d).

Interestingly, hormone levels seem to play a critical role in these erectile events (for review, see Andersen and Tufik 2006, 2008). Indeed, PSD decreases the level of testosterone, whereas progesterone levels were increased in both young and old groups, suggesting that, although sexual function commonly decreases with age, testosterone alone cannot be considered the main hormone involved in sexual activity (Andersen et al. 2002, 2003c, 2004a, b).

\section{Estrous CyCLE}

Thus far, little attention has been given to whether sleep is differentially regulated between genders and the magnitude of the consequences of sleep loss. Studies have documented that, while healthy women appear to have better sleep quality than men, they report more sleep problems, including inadequate sleep time and insomnia (Bixler et al. 2002, Zhang and Wing 2006). Moreover, nightmares were reported to be twice as frequent in women (Ohayon et al. 1997). The reasons for such discrepancies are attributed to hormonal fluctuations over the menstrual and estrous cycles, a factor that has been associated with sleep variations in both humans and rats (Hachul et al. 2006, Antunes et al. 2006, 2007).

In particular, alterations in reproductive hormone release coincidental with sleep have been suggested as a manifestation of entrained links between CNS regulation and endocrine function. Notably, our results demonstrate that female rats submitted to PSD in the diestrous phase (PSD-diestrous) had their estrous cycles disrupted during the recovery period. This was evidenced by a constant diestrus during the first week of recovery. As for hormone alterations, progesterone concentrations were statistically higher in PSD-diestrus compared to the respective phase control and to PSD-proestrous and PSD-estrous rats, while CTRL-metestrous rats had higher levels than CTRL-proestrous and estrous groups. In addition, the PSD-diestrous phase exhibited higher concentrations of corticosterone and lower estrogen levels than the respective control rats. These data indicate that PSD may modulate ovarian hormone released through alterations in hormonal-neurochemical systems.

\section{OXidative Stress}

Sleep has been described to provide an antioxidative function (Reimund 1994), which leads to the hypothesis that sleep deprivation is associated with an accumulation of free radicals. It is known that PSD induces 
a number of alterations in systemic and brain energy metabolism (Bergmann et al. 1989, Everson et al. 1994), as well as motor weakness, lesions in organs, and even death (Rechtschaffen et al. 1983). It is possible that these effects occur as a result of reactive oxygen species (ROS) accumulation. A number of studies have reported that ROS are involved in the pathogenesis of several diseases and psychological stress (Halliwell and Gutteridge 1989).

D'Almeida and coworkers have studied the oxidative stress status following PSD. First, they described a reduction in total glutathione (GSH) levels in the whole brain; however, a number of antioxidants were found to be unchanged in the brain after PSD (D'Almeida et al. 1997). Furthermore, reduced GSH levels were demonstrated in the hypothalamus and thalamus (D'Almeida et al. 1998), suggesting that these specific brain regions could be more susceptible to oxidative stress during PSD (D'Almeida et al. 2000). To investigate the hypotheses that (i) sleep involves a process of detoxification at the cellular level (Inoué et al. 1995) and (ii) that sleep may serve as an antioxidant function by removing free radicals or ROS produced during waking (Reimund 1994), and, considering that GSH levels were counteracted by melatonin administration (Floreani et al. 1997), the authors tested the effects of exogenous melatonin administration on the PSD-induced decrease in GSH. Twice daily administration of melatonin during the PSD period, and equivalent dosing in controls, resulted in similarly lowered hypothalamic GSH levels, indicating that the antioxidant properties of melatonin were not able to preserve hypothalamic GSH levels after PSD, and that exogenous melatonin may lead to decreases in hypothalamic GSH levels and further the decrease induced by PSD in this brain region (D'Almeida et al. 2000).

Reduced GSH levels, a key indicator of oxidative stress, have been shown to precipitate apoptotic cell death in the brain under different conditions (Tan et al. 1998). Based upon the above-described findings of D'Almeida and colleagues, a study was performed that showed that binding of the "peripheral-type" benzodiazepine ligand $\left[{ }^{3} \mathrm{H}\right] \mathrm{PK} 11195$ to reactive astrocytes, a reliable and sensitive index of necrotic changes, was not altered in 14 examined brain regions, and mRNA levels of the apoptosis-related genes bcl-2 and bax in any of 24 brain areas studied (Hipólide et al. 2002) were likewise unchanged. These findings suggest that the oxidative stress that develops in the brains of rats submitted to PSD does not result in cell loss.

Considering the stressful nature of the PSD method, which is associated with the disruption of various physiological processes, D'Almeida's group described that plasma homocysteine (an intermediate amino acid in methionine-cysteine metabolism) was reduced in PSD rats as compared with the cage group, and did not revert to normal levels after 24 or $48 \mathrm{~h}$ of recovery. Decreased glutathione and increased thiobarbituric acid reactive substance levels were observed in PSD rats (Oliveira et al. 2002). The authors suggested that the observed decreases in homocysteine levels may represent a self-correcting response to depleted glutathione in PSD rats, which would contribute to the attenuation of the deleterious effects of PSD. Homocysteine levels were decreased in older rats as compared to young ones; PSD did not further reduce the lowered levels in aged animals. Additionally, PSD had no effect on total cholesterol or folate levels, while it increased HDL, LDL, and vitamin $\mathrm{B}_{12}$, and decreased triglyceride and VLDL levels (Andersen et al. 2004c). Indeed, the increase in LDL levels, which was much more pronounced than the increase in HDL, would constitute an unfavorable factor since the LDL/ HDL ratio represents a better assessment of cardiovascular disease risk than HDL cholesterol levels alone (Lemieux et al. 2001). These results indicate that PSD has significant but heterogeneous physiological effects in aged rats, and it may intensify certain age-related effects that contribute to cardiovascular disease risk (Andersen et al. 2004c).

One of the most common sleep disorders, obstructive sleep apnea, is characterized by an airflow interruption despite persistent respiratory efforts, thus causing chronic sleep deprivation due to the frequent awakening at the termination of apneic episodes. As sleep deprivation may aggravate hypertensive features, and since cardiorespiratory changes are observed after PSD, Palma et al. (2002) studied the participation of endothelin-1 in the genesis of hypertension and heart disease by determining plasma endothelin-1/2 levels in PSD rats. The data evidenced that PSD altered endothelin- $1 / 2$ concen- 
trations, suggesting that the increase in the endothelin levels may be involved in the genesis of arterial hypertension and cardiorespiratory changes, which are observed after sleep deprivation (Palma et al. 2002).

It has been proposed that both hypoxia and sleep fragmentation are implicated in the cardiovascular risk associated with obstructive sleep apnea. Studies have demonstrated that hypoxia reduces delta and REM sleep and prolongs stages 1 and 2 of NREM sleep (Berssenbrugge et al. 1984). However, it is not possible to determine whether the effects of obstructive sleep apnea in humans are caused by hypoxia per se or whether they are due to the frequency of arousals induced by breathing alterations during sleep or both (Berssenbrugge et al. 1983). To address this issue, we have been conducting studies using intermittent hypoxia in rats. As described by Perry et al. (2007), subchronic exposure to intermittent hypoxia $\left(10 \% \mathrm{O}_{2}\right)$ did not affect the biochemical blood parameters related to cardiovascular risk, but subchronic PSD reduced triglyceride. These parameters remained reduced when PSD was combined with intermittent hypoxia. Further investigation into the association between hypoxia and sleep deprivation, which is known as sequelae of obstructive sleep apnea, may be useful in understanding the influence of both factors on the cardiovascular system.

\section{STRESS}

In addition to sleep deprivation, achieved by either the single platform method or variations, the techniques induce high levels of stress and have been a subject of debate. If sleep is essential for health and life, then sleep deprivation is a biological stressor. Indeed, some signs of sleep deprivation are weight loss, reduced thymus weight (Coenen and Van Luijtelaar 1985), increased adrenal weight (Coenen and Van Luijtelaar 1985, Suchecki and Tufik 2000), augmented corticosterone (Suchecki and Tufik 2000, Andersen et al. 2003c, 2004b, d, 2005a, Hipólide et al. 2006), and ACTH levels (Andersen et al. 2005a). Sleep deprivation produces a marked negative energy balance, indicating that hypercatabolism is a central effect of sleep deprivation in rats (Everson 1997) in addition to termorregulation alteration (Seabra and Tufik 1993, Hoshino 1996). Moreover, c-fos expression is increased in the preoptic area of cats submitted to the flower pot technique (Ledoux et al. 1996). Increased binding of CRF receptors in several brain areas and reduced hypothalamic CRF content is observed in sleep deprived rats (Fadda and Fratta 1997). As the sleep-wake cycle is distinctly affected by stress (Papale et al. 2005), further research is warranted to elucidate both how sleep is interrupted by stress and the long-term effects inflicted by sleep deprivation, an inherent stress condition, on the organism's coping skills.

\section{DEPRESSION}

Since its first experimental demonstration (Pflug and Tölle 1971), the antidepressant effect of sleep deprivation for one night has been widely investigated. After many years, the procedure of sleep deprivation has proven its efficacy for alleviating depression in approximately $60 \%$ of the cases after a single session, and in almost $90 \%$ after three sessions performed at one-week intervals (for review see Wu and Bunney 1990, WirzJustice and Van der Hoofdakker 1999). However, this effect is normally only transient, and, in most cases, relapse occurs after the first episode of recovery sleep (Southmayd et al. 1990). Despite the numerous studies of total sleep deprivation, and based on the theory that PS pressure is increased in depressed patients (Vogel et al. 1980), some attempts were made to evaluate the effects of selective PSD.

Apart from therapeutic PSD, the relationship between PSD effects and noradrenergic, serotonergic and other effects of antidepressant drugs has been investigated. In 1983, Tufik and Silveira-Filho demonstrated that PSD rats were more sensitive to imipramine and fluoxetine and also to nomifensive, which showed a biphasic effect. As has been suggested, PSD may underlie the clinical effects of antidepressants in the context of depression (Vogel 1975). Thus, potentiation of the therapeutic effects of antidepressants by PSD suggests that the depressants in clinical, as well as in locomotor activity (as used in this report) in rodents, share a common mechanism (Tufik and Silveira-Filho 1983). The development of anhedonia, characterized by loss of interest following rewarding stimuli, was recently studied by Pezzato et al. (unpublished data) in PSD rats since the occurrence of a depressive like-state may be an important factor to consider in sleep-deprived stud- 
ies. The results indicate that PSD promotes a progressive decrease in daily sucrose intake, whereas the increase in sucrose intake observed during the rebound period could be attributed to a change in the strategy of coping.

The majority of investigators have concluded that the immediate effect of a single session of sleep deprivation in humans is not influenced by the administration of antidepressant drugs (for review see Giedke and Schwärzler 2002, Adrien 2002). The common neurobiological mechanisms affected by pharmacological antidepressants and sleep deprivation suggest that sleep loss in some insomniac or depressed patients might be an endogenous compensatory process that is therapeutic rather than pathological. This proposal should open up new strategies for the treatment of depression (Adrien 2002).

\section{CONCLUSION}

Over the past few decades, a remarkable explosion of research has allowed us to construct a much more complete picture of the neurotransmitter, genetic, cellular, neurophysiological and behavioral changes that are affected by sleep deprivation.

Sleep deprivation seems to disrupt vital biological processes necessary for cognitive function and physical health, yet the ways in which the body is compromised are not fully understood. There is a pressure in modern society to carry out an increasing variety and number of activities during wakefulness. The expectation that these activities should be achieved tends to push sleep into background. This trends toward sleep deprivation and irregular sleep-wake patterns with resultant impaired concentration and memory reduces the quality of life and the ability to enjoy and complete activities. The balance may need to swing back toward awareness that adequate and regular sleep is required to promote a state of well-being during wakefulness. Once aware of this relationship, it becomes the responsibility of each individual to select his/her own combination of sleep and wakefulness by prioritizing the opportunities that present themselves every day.

\section{ACKNOWLEDGMENTS}

This work was supported by grants from the Associação Fundo de Incentivo à Psicofarmacologia (AFIP),
Conselho Nacional de Desenvolvimento Científico e Tecnológico (CNPq) and Fundação de Amparo à Pesquisa do Estado de São Paulo (FAPESP) Centros de Pesquisa Inovação e Difusão (CEPID) (\#98/14303-3 to ST). All authors are recipients of fellowships from $\mathrm{CNPq}$.

\section{RESUMO}

O sono ocupa cerca de um terço de nossas vidas, entretanto seu impacto na saúde e sua influência nas condições patológicas ainda não foi completamente elucidado. A prevalência dos distúrbios de sono é cada vez maior, sobretudo nas regiões mais industrializadas, repercutindo diretamente no bem-estar da população. Este artigo tem como objetivo sintetizar e atualizar a literatura a respeito do método de privação de sono paradoxal e seu panorama de conseqüências desde comportamentais até genéticas em animais. Ainda, destacamos a contribuição e relevância dos estudos experimentais realizados por nosso grupo nas ultimas três décadas.

Palavras-chave: sono, privação de sono, rebote, dopamina, ereção, corticosterona, memória.

\section{REFERENCES}

ADRIEN J. 2002. Neurobiological bases for the relation between sleep and depression. Sleep Med Rev 6: 341-351.

Alvarenga TA, Patti Cl, Andersen ML, Silva RH, Calzavara MB, Lopez GB, Frussa-Filho R AND TUFIK S. 2008. Paradoxical sleep deprivation impairs acquisition, consolidation, and retrieval of a discriminative avoidance task in rats. Neurobiol Learn Mem 90: $624-632$.

ANDERSEN ML AND TUFIK S. 2002. Distinct effects of paradoxical sleep deprivation and cocaine administration on sexual behavior in male rats. Addict Biol 7: 251-253.

ANDERSEN ML AND TUFIK S. 2005. The effects of dopaminergic agonists on genital reflexes in paradoxical sleep deprived male rats. Physiol Behav 84: 205-210.

Andersen ML AND TUFIK S. 2006. Does male sexual behavior require progesterone? Brain Res Rev 51: 136-143.

ANDERSEN ML AND TUFIK S. 2008. The effects of testosterone on sleep and sleep-disordered breathing in men: its bidirectional interaction with erectile function. Sleep Med Rev 12: 365-379.

Andersen ML, Palma BD, Rueda AD and Tufik S. 2000. The effects of acute cocaine administration in paradoxical sleep-deprived rats. Addict Biol 5: 417-420. 
Andersen ML, Bignotto M, Machado RB And TuFIK S. 2002. Does sleep deprivation and cocaine induce penile erection and ejaculation in old rats? Addict Biol 7: 285-290.

Andersen ML, Bignotto M And Tufik S. 2003a. Facilitation of ejaculation after methamphetamine administration in paradoxical sleep deprived rats. Brain Res 978: $31-37$.

Andersen ML, Bignotto M And Tufik S. 2003b. The effect of apomorphine on genital reflexes in male rats deprived of paradoxical sleep. Physiol Behav 80: 211-215.

Andersen ML, Bignotto M And Tufik S. 2003c. Influence of paradoxical sleep deprivation and cocaine on development of spontaneous penile reflexes in rats of different ages. Brain Res 968: 130-138.

Andersen ML, Bignotto M And Tufik S. 2003d. Cocaine-induced genital reflexes during paradoxical sleep deprivation and recovery. Physiol Behav 78: 255-259.

Andersen ML, Bignotto M, Papale LA And Tufik S. 2004a. Age-related effects on genital reflexes induced by paradoxical sleep deprivation and cocaine in rats. Exp Gerontol 39: 233-237.

Andersen ML, Bignotto M And Tufik S. 2004b. Hormone treatment facilitates penile erection in castrated rats after sleep deprivation and cocaine. J Neuroendocrinol 16: 154-159.

Andersen ML, Martins PJF, D'Almeida V, Santos RF, BignotTo M AND TUFIK S. 2004c. Effects of paradoxical sleep deprivation on blood parameters associated with cardiovascular risk in aged rats. Exp Gerontol 39: 817-824.

Andersen ML, Bignotto M, Machado RB AND Tufik S. 2004d. Different stress modalities result in distinct steroid hormone responses by male rats. Braz J Med Biol Res 37: 791-797.

Andersen ML, Martins PJF, D’Almeida V, BignotTO M AND TUFIK S. 2005a. Endocrinological alterations during sleep deprivation and recovery in male rats. J Sleep Res 14: 83-90.

Andersen ML, Perry JC And Tufik S. 2005b. Acute cocaine effects in paradoxical sleep deprived male rats. Prog Neuro-Psychopharmacol Biol Psych 29: 245-251.

Andersen ML, Ribeiro DA, Bergamaschi CT, AlVAREnga TA, Silva A, Zager A, CAMpos RR AND TUFIK S. 2009. Distinct effects of acute and chronic sleep loss on DNA damage in rats. Prog Neuropsychopharmacol Biol Psychiatry 33: 562-567.
Antunes IB, Andersen ML, Baracat EC And Tufik S. 2006. The effects of paradoxical sleep deprivation on estrous cycles of the female rats. Horm Behav 49: $433-440$.

Antunes IB, Andersen ML, Alvarenga TAF And TUFIK S. 2007. Effects of paradoxical sleep deprivation on blood parameters associated with cardiovascular risk in intact and ovariectomized rats compared with male rats. Behav Brain Res 176: 187-192.

Asakura W, Matsumoto K, Ohta H and Watanabe H. 1992. REM sleep deprivation decreases apomorphineinduced stimulation of locomotor activity but not stereotyped behavior in mice. Gen Pharmacol 23: 337-341.

Aston-Jones G, Chen S, ZHU Y And Oshinsky ML. 2001. A neural circuit for circadian regulation of arousal. Nat Neurosci 4: 732-738.

Bergmann BM, Everson CA, Kushida CA, FAng VS, Leitch CA, Schoeller DA, Refetoff S AND RECHTSCHAFFEN A. 1989. Sleep deprivation in the rat: V. Energy use and mediation. Sleep 12: 31-41.

Berssenbrugge A, Dempsey J, Iber C, Skatrud J And WILSON P. 1983 Mechanisms of hypoxia-induced periodic breathing during sleep in humans. J Physiol 343: 507-526.

Berssenbrugge A, Dempsey J And Skatrud J. 1984. Effects of sleep state on ventilatory acclimatization to hypoxia in humans. J Appl Physiol 57: 1089-1096.

Bitran D AND Hull EM. 1987. Pharmacological analysis of male rat sexual behavior. Neurosci Biobehav Rev 11: $365-389$.

Bixler EO, Vgontzas AN, Lin HM, Vela-Bueno A AND KALES A. 2002. Insomnia in central Pennsylvania. J Psychosom Res 53: 589-592.

Bueno OFA, Lobo LL, OLIVEIRA MGM, Gugliano EB, POMARICO AC AND TUFIK S. 1994. Dissociated paradoxical sleep deprivation effects on inhibitory avoidance and conditioned fear. Physiol Behav 56: 775-779.

Bueno OFA, Oliveira MGM, Lobo LL, Morais PR, Melo FHM AND TUFIK S. 2000. Cholinergic modulation of inhibitory avoidance impairment induced by paradoxical sleep deprivation. Prog Neuropsychopharmacol Biol Psychiatr 24: 595-606.

CARlini EA, Lindsey CJ And Tufik S. 1977. Cannabis, catecholamines, rapid eye movement sleep and aggressive behaviour. Br J Pharmacol 61: 371-379.

Cirelli C. 2002. How sleep deprivation affects gene expression in the brain: a review of recent findings. J Appl Physiol 92: 394-400. 
CiRELLi C. 2006. Cellular consequences of sleep deprivation in the brain. Sleep Med Rev 10: 307-321.

Cirelli C, Gutierrez CM and Tononi G. 2004. Extensive and divergent effects of sleep and wakefulness on brain gene expression. Neuron 41: 35-43.

Clark CR, GefFen GM And GefFen LB. 1987. Catecholamines and attention I: animal and clinical studies. Neurosci Biobehav Rev 11: 341-352.

Coenen AM And van LuiJtelaAR EL. 1985. Stress induced by three procedures of deprivation of paradoxical sleep. Physiol Behav 35: 501-504.

Cohen HB And Dement WC. 1965. Sleep: changes in threshold to electroconvulsive shock in rats after deprivation of "paradoxical" phase. Science 150: 1318-1319.

D’Almeida V, Hipólide DC, Azzalis LA, Lobo LL, JUNQUEIRA VBC AND TUFIK S. 1997. Absence of oxidative stress following paradoxical sleep deprivation in rats. Neurosci Lett 235: 25-28.

D’Almeida V, Lobo Ll, Hipólide DC, Oliveira AC, Nobrega JN AND TUFIK S. 1998. Sleep deprivation induces brain region-specific decreases in glutathione levels. Neuroreport 9: 2853-2856.

D’Almeida V, Hipólide DC, Lobo Ll, Oliveira AC, Nobrega JN AND TUFIK S. 2000. Melatonin treatment does not prevent decreases in brain glutathione levels induced by sleep deprivation. Eur J Pharmacol 390: 299-302.

D'Almeida V, Hipólide DC, Raymond R, BARlow KB, Parkes JH, Pedrazzoli M, Tufik S AND Nobrega JN. 2005. Opposite effects of sleep rebound on orexin $\mathrm{OX}_{1}$ and $\mathrm{OX}_{2}$ receptor expression in rat brain. Mol Brain Res 136: 148-157.

DE KLOET ER. 1991. Brain corticosteroid receptor balance and homeostatic control. In: GANONG WF, MATINI L (Eds), Frontiers of Neuroendocrinology, New York: Raven Press 12: 95-164.

DE MEllo MT ET AL. 2000. Sleep patterns and sleep-related complaints Of Brazilian Interestate Bus Drivers. Braz J Med Biol Res 33: 71-77.

de Mello MT, Bittencourt LRA, Cunha RC, EsTeves AM AND TUfIK S. 2009. Sleep and Transit in Brazil: New Legislation. J Clin Sleep Med 5: 164-166.

Dement W. 1960. The effect of dream deprivation. Science 131: 1705-1707.

Ellman SJ, Spielman AJ, Luck D, Steiner SS ANd HALPERIN R. 1978. REM deprivation: a review. In:
Ellman SJ AND Antrobus JS (Eds), The mind in sleep: psychology and psychopathology, $2^{\text {nd }}$ ed., New York: J Wiley \& Sons, p. 329-369.

Everson CA. 1997. Clinical manifestations of prolonged sleep deprivation. In: SchWARTz WJ (Ed), Sleep science: integrating basic research and clinical practice. Monogr Clin Neurosci. Basel, Karger 15: 34-59.

Everson CA, Smith CB And Sokoloff L. 1994. Effects of prolonged sleep deprivation on local rates of cerebral energy metabolism in freely moving rats. J Neurosci 14 : 6769-6778.

FADDA P AND FRATTA W. 1997. Stress-induced sleep deprivation modifies corticotropin releasing factor (CRF) levels and CRF binding in rat brain and pituitary. Pharmacol Res 35: 443-446.

FAROoQUi SM, BRock JW AND ZHOU J. 1996. Changes in monoamines and their metabolite concentrations in REM sleep-deprived rat forebrain nuclei. Pharmacol Biochem Behav 54: 385-391.

Ferrari W, Gessa GL AND VARgiU L. 1963. Behavioral effects induced by intracisternally injected ACTH and MSH. Ann NY Acad Sci 104: 330-345.

FLOREANI M, SKAPER SD, FACCI L, LIPARTITI M AND GIUSTI P. 1997. Melatonin maintains glutathione homeostasis in kainic-acid-exposed rat brain tissues. FASEB J 11: $1309-1315$.

Frussa-Filho R, Gonçalves MT, Andersen ML, DE Araujo NP, Chinen CC AND Tufik S. 2004. Paradoxical sleep deprivation potentiates amphetamine-induced behavioural sensitization by increasing its conditioned component. Brain Res 1003: 188-193.

GHOSH PK, HRdinA PD AND LING GM. 1976. Effects of REMS deprivation on striatal dopamine and acetylcholine in rats. Pharmacol Biochem Behav 4: 401-405.

GIEDKE H AND SCHWÄRZLER F. 2002. Therapeutic use of sleep deprivation in depression. Sleep Med Rev 6: 361377.

Guindalini C, Andersen ML, Alvarenga T, Lee K AND TUFIK S. 2009. To what extent is sleep rebound effective in reversing the effects of paradoxical sleep deprivation on gene expression in the brain? Behav Brain Res 201: 53-58.

Hachul de Campos H, Brandão LC, D'Almeida V, Grego BHC, BitTencourt LR, TuFiK S AND BARACAT EC. 2006. Sleep disturbances, oxidative stress and cardiovascular risk parameters in postmenopausal women complaining of insomnia. Climacteric 9: 312-319. 
Halliwell B AND GutTeridge JMC. 1989. Free radicals in biology and medicine, $2^{\text {nd }}$ ed., Oxford: Clarendon Press, $543 \mathrm{p}$.

Hicks RA AND PAulus MJ. 1973. Effects of rapid eye movement sleep deprivation on the performance of rats in a T-maze. Psychol Rec 23: 89-92.

Hicks RA, OKudA A And Thomsen D. 1977. Depriving rats of REM sleep: the identification of a methodological problem. Am J Psychol 90: 95-102.

Hipólide DC, TUFIK S, RAYMOND R AND NobREGA JN. 1998. Heterogeneous effects of rapid eye movement sleep deprivation on binding to $\alpha$ - and $\beta$-adrenergic receptor subtypes in rat brain. Neuroscience 86: 977-987.

Hipólide DC, Lobo LL, Medeiros R, Neumann B AND TUFIK S. 1999. Treatment with dexamethasone alters yawning behavior induced by cholinergic but not dopaminergic agonist. Physiol Behav 65: 829-832.

Hipólide DC, D'Almeida V, RAYMONd R, TUFIK S AND Nobrega JN. 2002. Sleep deprivation does not affect indices of necrosis or apoptosis in rat brain. Int J Neurosci 112: $155-166$.

Hipólide DC, Moreira KM, Barlow KB, Wilson AA, NobregA JN AND TUFIK S. 2005. Distinct effects of sleep deprivation on binding to norepinephrine and serotonin transporters in rat brain. Prog Neuropsychopharmacol Biol Psychiatry 29: 297-303.

Hipólide DC, Suchecki D, Pinto APC, Faria EC, TUFIK S AND LUZ J. 2006. Paradoxical sleep deprivation and sleep recovery: effects on the hypothalamicpituitary-adrenal axis activity, energy balance and body composition of rats. J Neuroendocrinol 18: 231-238.

Hobson JA, Pace-Schott EF And Stickgold R. 2000. Dreaming and the brain: toward a cognitive neuroscience of conscious states. Behav Brain Sci 23: 793-842.

Horvath Tl, Peyron C, Diano S, Ivanov A, AstonJones G, Kilduff TS AND VAN DEN Pol AN. 1999. Hypocretin (orexin) activation and synaptic innervation of the locus coeruleus noradrenergic system. J Comp Neurol 415: $145-159$.

Hoshino K. 1996. Food deprivation and hypothermia in desynchronized sleep-deprived rats. Braz J Med Biol Res 29: 41-46.

InOUÉ S, HondA K AND KomodA Y. 1995. Sleep as neuronal detoxification and restitution. Behav Brain Res 69: 91-96.

Jouvet D, Vilmont P, Delorme F And Jouvet M. 1964. Etude de la privation selective de la phase para- doxale de sommeil chez le chat. Compt Rend soc Biol 158: 756-759.

Jouvet M. 1998. Paradoxical sleep as a programming system. J Sleep Res 7: 1-5.

Kilduff TS AND PEYRON C. 2000. The hypocretin/orexin ligand-receptor system: implications for sleep and sleep disorders. Trends Neurosci 23: 359-365.

LANDIS C. 1996. Altered sleep patterns with the platform method of REM sleep deprivation in rats. Sleep Res 25: 469.

Ledoux L, Sastre JP, Buda C, Luppi PH And Jouvet M. 1996. Alterations in c-fos expression after different experimental procedures of sleep deprivation in the cat. Brain Res 735: 108-118.

Lee KS, Alvarenga TA, Guindalini C, Andersen ML, CASTRO R AND TUFIK S. 2009. Validation of commonly used reference genes for sleep-related gene expression studies. BMC Molecular Biology 10: 45.

Lemieux I, Lamarche B, Couillard C, Pascot A, Cantin B, Bergeron J, Dagenais GR and DesPRÉS JP. 2001. Total cholesterol/HDL cholesterol ratio vs LDL cholesterol/HDL cholesterol ratio as indices of ischemic heart disease risk in men: the Quebec Cardiovascular Study. Arch Intern Med 161: 2685-2692.

Lobo LL, Neumann BG, EIdman DS And Tufik S. 1990. Effects of REM sleep deprivation on ACTH-induced yawning. Pharmacology 40: 174-178.

Lobo Ll, Medeiros R, Hipólide DC And Tufik S. 1995. Atropine increases pilocarpine-induced yawning behavior in paradoxical sleep deprived rats. Pharmacol Biochem Behav 52: 485-488.

Machado RB, Hipólide DC, Benedito-Silva AA AND TUFIK S. 2004. Sleep deprivation induced by the modified multiple platform technique: quantification of sleep loss and recovery. Brain Res 1004: 45-51.

Machado RB, Suchecki D And Tufik S. 2005. Sleep homeostasis in rats assessed by a long-term intermittent paradoxical sleep deprivation protocol. Behav Brain Res 160: 356-364.

Maret S, Dorsaz S, Gurcel L, Pradervand S, Petit B, Pfister C, Hagenbuchle O, O’Hara BF, Franken P And TAfti M. 2007. Homerla is a core brain molecular correlate of sleep loss. Proc Natl Acad Sci USA 104: 20090-20095.

Martins PJF, Mello MT and TufiK S. 2001. Exercício e sono. Rev Bras Med Esporte 7: 28-36. 
Martins PJ, Nobrega JN, Tufik S ANd D’Almeida V. 2008. Sleep deprivation-induced gnawing-relationship to changes in feeding behavior in rats. Physiol Behav 93: 229-234.

Mendelson WB, Guthrie RD, Frederick G AND WYATT RJ. 1974. The flower pot technique of rapid eye movement (REM) sleep deprivation. Pharmacol Biochem Behav 2: 553-556.

Miró E, Cano-Lozano MC And Buela-Casal G. 2002. Electrodermal activity during total sleep deprivation and its relationship with other activation and performance measures. J Sleep Res 11: 105-112.

Mogilnicka E And KlimeK V. 1977. Drugs affecting dopamine neurons and yawning behavior. Pharmacol Biochem Behav 7: 303-305.

Mogilnicka E, Wedzony K, Klimek V And Czyrak A. 1986. Desipramine induces yawning behaviour in rats. Neuropharmacology. 25: 783-786.

Morden B, Mitchell G And Dement W. 1967. Selective REM sleep deprivation and compensation phenomena in the rat. Brain Res 5: 339-349.

Morden B, Mullins R, Levine S, Cohen H And DeMENT W. 1968. Effect of REM deprivation on the mating behavior of male rats. Psychophysiology 5: 241-242.

Moreira KM, Hipólide DC, Nóbrega JN, Bueno OFA, Tufik S AND Oliveira MGM. 2003. Deficits in avoidance responding after paradoxical sleep deprivation are not associated with altered $[3 \mathrm{H}]$ pirenzepine binding to M1 muscarinic receptors in rat brain. Brain Res 977: 31-37.

NaKamura-Palacios EM, Bueno OFA, Takahashi RN AND TUFIK S. 2002. Acute or chronic effects of cannabinoids on spontaneous or pharmacologically induced yawning in rats. Pharmacol Biochem Behav 74: 205-212.

Neumann BG, Troncone LRP, Braz S And Tufik S. 1990. Modifications on dopaminergic and cholinergic systems induced by the water tank technique: analysis through yawning behavior. Arch Int Pharmacodyn 308: 32-38.

NUNES JR GP AND TUFIK S. 1994a. Validation of the modified multiple platform method (MMP) of paradoxical sleep deprivation in rats. Sleep Res 23: 419.

Nunes JR GP, TufiK S AND Nobrega JN. 1994b. Autoradiographic analysis of D1 and D2 dopaminergic receptors in rat brain after paradoxical sleep deprivation. Brain Res Bull 34: 453-456.
Nunes JR GP, Tufik S AND Nobrega JN. 1994c. Decreased muscarinic receptor binding in rat brain after paradoxical sleep deprivation: an autoradiographic study. Brain Res 645: 247-252.

OHAYon MM, Morselli PL and Guilleminault C. 1997. Prevalence of nightmares and their relationship to psychopathology and daytime functioning in insomnia subjects. Sleep 20: 340-348.

Oliveira AC, D’Almeida V, Hipólide DC, Nobrega JN AND TUFIK S. 2002. Sleep deprivation reduces total plasma homocysteine levels in rats. Can J Physiol Pharmacol 80: 193-197.

Palma BD, Suchecki D and TuFIK S. 2000. Differential effects of acute cold and footshock on the sleep of rats. Brain Res 861: 97-104.

Palma BD, Gabriel Jr A, Bignotto M and Tufik S. 2002. Paradoxical sleep deprivation increases plasma endothelin levels. Braz J Med Biol Res 35: 75-79.

Papale LA, Andersen ML, Antunes IB, Alvarenga TAF AND TUFIK S. 2005. Sleep pattern in rats under different stress modalities. Brain Res 1060: 47-54.

Pedrazzoli M, D'Almeida V, Martins PJF, MachaDo RB, Ling L, Nishino S, Tufik S AND Mignot E. 2004. Increased hypocretin-1 levels in cerebrospinal fluid after REM sleep deprivation. Brain Res 995: 1-6.

Perry JC, D'Almeida V, Souza FG, Schoorlemmer GH, COlumbari E AND TUFIK S. 2007. Consequences of subchronic and chronic exposure to intermittent hypoxia and sleep deprivation on cardiovascular risk factors in rats. Respir Physiol Neurobiol 156: 250-258.

Pflug B AND Tölle R. 1971. Disturbance of the 24-hour rythm in endogenous depression and the treatment of endogenous depression by sleep deprivation. Int Pharmacopsychiatry 6: 187-196.

Piper DC, Upton N, Smith MJ And Hunter AJ. 2000. The novel brain neuropeptide, orexin-A, modulates the sleep-wake cycle of rats. Eur J Neurosci 12: 726-730.

Pires MlN, Benedito-Silva AA, Mello MT, Del Giglio S, Pompéia C And TuFIK S. 2007. Sleep habits and complaints of adults in the city of São Paulo, Brazil, in 1987 and 1995. Braz J Med Biol Res 40: 1505-1515.

Rechtschaffen A, Gilliland MA, Bergmann BM AND Winter JB. 1983. Physiological correlates of prolonged sleep deprivation in rats. Science 221: 182-184.

Rechtschaffen A, Bergmann BM, Gilliland MA AND BAUER K. 1999. Effects of method, duration, and 
sleep stage on rebounds from sleep deprivation in the rat. Sleep 22: 11-31.

REIMUND E. 1994. The free radical flux theory of sleep. Med Hypotheses 43: 231-233.

Santos EH, Mello MT, Pradella-Hallinan M, LuChesi L, Pires ML AND TUFIK S. 2004. Sleep and sleepiness among Brazilian shift-working bus drivers. Chronobiol Int 21: 881-888.

Seabra ML and TUfIK S. 1993. Sodium diclofenac inhibits hyperthermia induced by paradoxical sleep deprivation: the possible participation of prostaglandins. Physiol Behav 54: 923-926.

SHNEERSON JM. 2000. Handbook of sleep medicine. Oxford: Blackwell Science, $237 \mathrm{p}$.

SILVA RH AND FRUSSA-FILHO R. 2000. The plus-maze discriminative avoidance task: a new model to study memoryanxiety interactions. Effects of chlordiazepoxide and caffeine. J Neurosci Methods 102: 117-125.

SILVA RH ET AL. 2004a. Role of hippocampal oxidative stress in memory deficits induced by sleep deprivation in mice. Neuropharmacol 46: 895-903.

Silva RH, Chehin AB, Kameda SR, Takatsu-ColeMAN AL, ABILIO VC, TUFIK S AND Frussa-Filho R. 2004b. Effects of pre- or post-training paradoxical sleep deprivation on two animal models of learning and memory in mice. Neurobiol Learn Mem 82: 90-98.

SMith C. 1985. Sleep stages and learning: a review of the animal literature. Neurosci Biobehav Rev 9: 157-168.

SMith C AND Wong PT. 1991. Paradoxical sleep increases predict successful learning in a complex operant task. Behav Neurosci 105: 282-288.

Southmayd SE, DAVid MM, CAIRns J, Delva NJ, LETEMENDIA FJ AND WALDRON JJ. 1990. Sleep deprivation in depression: pattern of relapse and characteristics of preceding sleep. Biol Psychiatry 28: 979-988.

Spiegel K, Leproult R ANd VAn CAuter E. 1999. Impact of sleep debt on metabolic and endocrine function. Lancet 354: 1435-1439.

STEINER SS AND ELLMAN SJ. 1972. Relation between REM sleep and intracranial self-stimulation. Science 177: $1122-1124$.

STERN WC. 1971. Acquisition impairments following rapid eye movement sleep deprivation in rats. Physiol Behav 7: 345-352.

Stickgold R AND WALKER MP. 2007. Sleep-dependent memory consolidation and reconsolidation. Sleep Med 8: 331-343.
SUCKECKI D AND TUFIK S. 2000. Social stability attenuates the stress in the modified multiple platform method for paradoxical sleep deprivation in the rat. Physiol Behav 68: 309-316.

Suchecki D, TibA PA AND TUFIK S. 2002. Hormonal and behavioural responses of paradoxical sleep-deprived rats to the elevated plus maze. J Neuroendocrinol 14: 549554.

SutCliffe JG AND DE LECEA L. 2002. The hypocretins: setting the arousal threshold. Nat Rev Neurosci 3: 339349.

TAN S, WoOd MM ANd MAHER P. 1998. Oxidative stress induces a form of programmed cell death with characteristics of both apoptosis and necrosis in neuronal cells. J Neurochemistr 71: 95-105.

Terao A, Huang ZL, Wisor JP, Mochizuki T, GeRASHCHENKo D, URADE Y AND KILDUfF TS. 2008. Gene expression in the rat brain during prostaglandin D2 and adenosinergically-induced sleep. J Neurochem 105: 1480-98.

TRONCONE LRP AND TUFIK S. 1991. Effects of selective adrenoceptor agonists and antagonists on aggressive behavior elicited by apomorphine, DL-DOPA and fusaric acid in REM-sleep deprived rats. Physiol Behav 50: 173178.

TRONCONE LRP, BRAZ S, BENEDITO MAC AND TUFIK S. 1986. REM sleep deprivation induces a decrease in norepinephrine-stimulated 3H-Cyclic AMP accumulation in slices from rat brain. Pharmacol Biochem Behav 25: 223-225.

Troncone LRP, FERreira TMS, Braz S, SilveiraFILHO NG AND TUFIK S. 1988. Reversal of the increase in apomorphine-induced stereotypy and aggression in REM sleep deprived rats by dopamine agonist pretreatments. Psychopharmacology 94: 79-83.

TUFIK S. 1981a. Changes of response to dopaminergic drugs in rats submitted to REM-sleep deprivation. Psychopharmacology 72: 257-260.

TUFIK S. 1981b. Increased responsiveness to apomorphine after REM sleep deprivation: supersensitivity of dopamine receptors or increase in dopamine turnover? J Pharm Pharmacol 33: 732-738.

TUFIK S AND SILVEIRA-FILHO NG. 1983. The influence of REM sleep deprivation in antidepressive drug action. Res Commun Psychol Psychiatr Behav 8: 331-341.

TufiK S, LINDSEY CJ AND CARLINI EA. 1978. Does REM sleep deprivation induce a supersensitivity of dopaminergic receptors in the rat brain? Pharmacology 16: 98-105. 
TUFIK S, TRONCONE LRP, BRAZ S, SILVA-FILHO AR AND NeUmann BG. 1987. Does REM sleep deprivation induce subsensitivity of presynaptic dopamine or postsynaptic acetylcholine receptors in the rat brain? Eur J Pharmacol 140: 215-219.

Tufik S, Nathan CL, Neumann B, Hipólide DC, Lobo LL, Medeiros R, Troncone LRP, Braz S AND SUCHECKI D. 1995. Effects of stress on drug-induced yawning: constant $v$ s. intermittent stress. Physiol Behav 58: 181-184.

UrbÁ-Holmgren R, GonzÁlez RM AND Holmgren B. 1977. Is yawning a cholinergic response? Nature 267: 261-262.

van Hulzen ZJM And Coenen AML. 1979. Selective deprivation of paradoxical sleep and consolidation of shuttle-box avoidance. Physiol Behav 23: 821-826.

VAN Hulzen ZJM AND Coenen AML. 1981. Paradoxical sleep deprivation and locomotor activity in rats. Physiol Beha 27: 741-744.

VAn LuiJtellar EL And Coenen AM. 1984. An EEG averaging technique for automated sleep-wake stage identification in the rat. Physiol Behav 33: 837-841.

Vogel GW. 1975. A review of REM sleep deprivation. Arch Gen Psychiatry 32: 749-761.
Vogel GW, Vogel F, McAbee RS And Thurmond AJ. 1980. Improvement of depression by REM sleep deprivation. New findings and a theory. Arch Gen Psychiatry 37: 247-253.

Wirz-Justice A AND VAN DEN HOOFDAKKer RH. 1999. Sleep deprivation in depression: what do we know, where do we go? Biol Psychiatry 46: 445-453.

Wood PL, Cheney DL And Costa E. 1979. Modulation of the turnover rate of hippocampal acetylcholine by neuropeptides: possible site of action of $\alpha$-melanocitestimulating hormone, adrenocorticotropic hormone and somatostatin. J Pharmacol Exp Ther 209: 97-103.

WU JC AND BUNNEY WE. 1990. The biological basis of an antidepressant response to sleep deprivation and relapse: review and hypothesis. Am J Psychiatry 147: 14-21.

YAMADA K AND FURUKAWA T. 1981. The yawning elicited by $\alpha$-melanocite-stimulating hormone involves serotonergic-dopaminergic-cholinergic neuron link in rats. Naunyn-Schmiedeberg's Arch Pharmacol 316: 155-160.

ZHANG B AND Wing YK. 2006. Sex differences in insomnia: a meta-analysis. Sleep 29: 85-93. 